\title{
Cryptococcal meningitis and cerebral toxoplasmosis in a patient with acquired immune deficiency syndrome
}

\author{
FRED BAHLS, SM SUMI
}

From the Division of Neurology, Department of Medicine, Harborview Medical Center and the Laboratory of Neuropathology, Department of Pathology, both of the School of Medicine, University of Washington, Seattle, Washington, USA

SUMMARY A 34-year-old homosexual male developed cryptococcal meningitis as the initial manifestation of Acquired Immune Deficiency Syndrome (AIDS). With antifungal therapy he improved. Six weeks later he developed focal motor seizures and progressive hemiplegia. Computer assisted tomography revealed multiple, ring-enhancing, low density lesions. The patient expired and at necropsy he was found to have multiple toxoplasma brain abscesses as well as chronic cryptoz coccal meningitis. This case demonstrates that in a patient with AIDS with pre-existing centra nervous system infection who develops new neurological symptoms the possibility of a second and potentially treatable infection must be considered and its diagnosis pursued vigorously.

Neurologic complications in the acquired immune deficiency syndrome (AIDS), both infectious and neoplastic, are well-recognised ${ }^{12}$ and occur in approximately $30 \%,{ }^{12}$ being the presenting symptom in $10-30 \% .{ }^{13}$ These infections may be by any opportunistic organism ${ }^{4}$ and often are due to more than one organism. ${ }^{5}$ Although the association of central nervous system infections with extraneural infections by the same or different organisms has been noted, ${ }^{12}$ documented infections of the CNS by more than one organism is rare. We describe an AIDS patient with cryptococcal meningitis and cerebral toxoplasmosis.

\section{Case report}

This 34-year-old homosexual male was admitted on 12 January 1984 with a two-week history of nausea and vomiting, headache, stiff neck, photophobia and a 10-pound $(5 \mathrm{~kg})$ weight loss. He had oral candidiasis, mild nuchal rigidity,

\footnotetext{
Address for reprint requests: SM Sumi, MD, Division of Neurology, Harborview Medical Center, 325 Ninth Avenue, Seattle, Washington 98104, USA.
}

Received 4 January 1985 and in revised form 8 March 1985. Accepted 23 March 1985 bilateral shotty inguinal lymph nodes and moderate hep tosplenomegaly. He was afebrile. Neurologic examination showed only intermittent mild confusion.

The following were normal: chest radiograph, electrolytes, alkaline phosphatase, haematocrit and platelet count. The white blood count was $4900 / \mathrm{mm}^{3}$. Lumbar puncture revealed an opening pressure of $370 \mathrm{~mm}$, protein $102 \mathrm{mg} / 100$ $\mathrm{ml}$, glucose $32 \mathrm{mg} / 100 \mathrm{ml}$, and 58 white blood cells $/ \mathrm{mm}^{3}$ (93\% lymphocytes). India ink examination revealed multiple cryptococci, and cryptococcal antigen was positive at a titre of 1:2048. The patient was treated with amphotericin B and 5 -fluorocytosine. Skin test was positive for candida, but negative for tricophyton and PPD, and there was a positive serology for cytomegalovirus. The ratio of helper $(5 \%)$ to suppressor $(67 \%) \mathrm{T}$ cells was abnormal, consistent with the diagnosis of AIDS. ${ }^{6}$ The patient was discharged on $29 \mathrm{Jan}$ uary 1984 on amphotericin B and 5-fluorocytosine. Lumbar puncture on 26 February had a protein of $31 \mathrm{mg} / 100 \mathrm{ml}$, normal glucose level, 15 white blood cells $/ \mathrm{mm}^{3}(100 \%$ lymphocytes) and positive India ink examination. Cryptococcal antigen titre was 1:32. Two days later the patient developed left arm and leg spasms lasting five minutes.

On 13 March he was re-admitted with headache, nausea $\frac{D}{O}$ and vomiting, progressive weakness and incoordination of the left arm, visual blurring and occasional scotomata. Gen- $N$ eral examination was unchanged. Neck was supple. The patient was alert and fully oriented with clear speech, but 


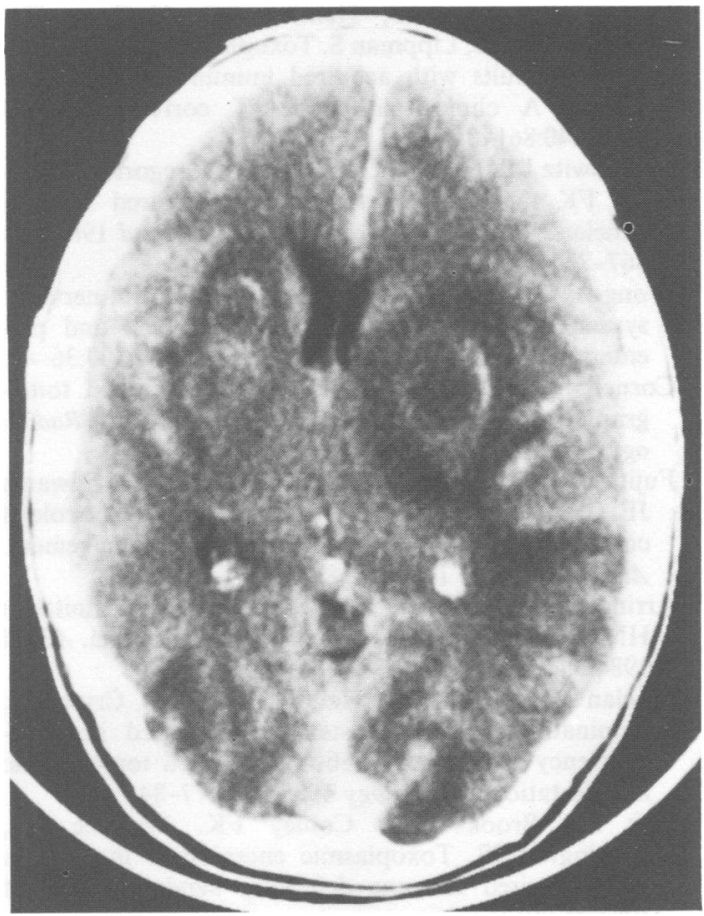

Fig Head CT scan showing contrast-enhancing ring lesions with oedema in both basal ganglia.

with slowed verbal responses. The nasal margins of the optic discs were slightly blurred. Visual fields were full to confrontation, but he extinguished the left field on double simultaneous stimulation. There was mild left central facial paresis and moderate left hemiparesis. He extinguished to pinprick and touch on the left on double simultaneous stimulation. Proprioception was impaired in the left hand. Reflexes were brisk bilaterally and plantar responses were flexor. Computed tomography revealed multiple ring-enhancing low density lesions with surrounding areas of decreased density (fig). On 16 March he became unresponsive and a right parietal brain biopsy was obtained. Following the biopsy, the patient was comatose, the pupils were dilated and nonreactive to light, and brainstem reflexes were absent. He died the following day.

Necropsy findings included finely nodular cirrhosis and splenomegaly. The brain biopsy showed thickened meninges infiltrated by a small number of lymphocytes. Many round to oval yeast-like forms were present in the meninges.

After fixation the brain weighed $1375 \mathrm{~g}$. The leptomeninges were diffusely cloudy with yellow-green exudate along some of the cerebral veins. The brain was swollen with bilateral uncal herniation and midbrain compression. A fresh operative defect was present in the right inferior parietal region. Coronal sections of the cerebral hemispheres revealed numerous well-demarcated areas of round, granular-appearing necrotic lesions, the largest of which were in the left and right putamen, and in the cortex of the right medial frontal lobe and right parieto-occipital lobe. These lesions consisted of large areas of coagulative necrosis with perivascular infiltration by lymphocytes in the adjacent blood vessels. At the margins of the necrosis there were numerous toxoplasma organisms scattered singly and only rarely forming clusters or pseudocysts. No cryptococcal organisms were identified in these abscesses but they were readily found in the overlying meninges.

\section{Discussion}

Documented simultaneous or sequential infection of the CNS by more than a single organism, even in immunocompromised patients, is rare. Among 39 such patients, Hooper et $\mathrm{al}^{7}$ found only six patients who had had sequential infection of the CNS by two different organisms. In contrast 19 patients had infection at an extraneural site by a second organism. Polymicrobial involvement of the CNS has been reported rarely in patients with AIDS. Levy et $a l^{8}$ described two patients with CNS infection, one with cytomegalovirus and toxoplasma and the other with cytomegalovirus and cryptococcus. However, except for the patient mentioned by Pitchenick et $a l^{9}$ with tuberculous brain abscess and subsequent toxoplasma encephalitis, a patient described by Post $e t a l^{10}$ with toxoplasmosis and a prior history of cryptococcal meningitis, and two patients described by Moskowitz et $a^{11}$ with toxoplasma encephalitis and acid fast bacillus infection, the patient reported here is the first with documented multiple non-viral infections of the CNS in a patient with AIDS.

Cryptococcus and toxoplasma are both common causes of infections in patients with AIDS. Toxoplasmosis is very common in this population and is the leading cause of focal brain lesions. ${ }^{11012}$ The diagnosis of the multifocal lesions in our patient was complicated by the known presence of cryptococcal meningitis, since single or multiple cryptococcal granulomas of the CNS occur in association with meningitis. ${ }^{813-15}$ Although the lesions in our patient were typical of those produced by toxoplasmosis, this diagnosis cannot be made on CT appearance alone; since lymphoma, other neoplasms, and other infectious agents can produce similar pictures, ${ }^{8101617}$ emphasising the need for a diagnostic brain biopsy.

The failure of the brain biopsy to identify toxoplasmosis in this case was probably because it was a superficial biopsy from an unaffected area. Even when a lesion is biopsied, identification of toxoplasma trophozoites can be difficult. ${ }^{1718}$ However, biopsy remains the best means of diagnosis, since serologic tests are often non-diagnostic in AIDS patients. ${ }^{811}$

We thank Dr DD Reichenback, who performed the neuropsy and made the brain and his findings available to us. 


\section{References}

${ }^{1}$ Britton CB, Miller, JR. Neurologic complications in acquired immunodeficiency syndrome (AIDS). Neurol Clin 1984:2:315-39.

${ }^{2}$ Snider WD, Simpson DM, Nielsen S, Gold JWN, Metroka CE, Posner JB. Neurological complications of acquired immune deficiency syndrome: Analysis of 50 patients. Ann Neurol 1983:14:403-18.

${ }^{3}$ Berger JR, Moskowitz L, Fisch M, Kelley RE. The neurologic complications of AIDS: Frequently the initial manifestation (abstract). Neurology (NY) 1984:34 (Suppl 1):134-5.

${ }^{4}$ Fauci AS, Macher AM, Longo DL, et al. Acquired immunodeficiency syndrome: epidemiologic, clinical, immunologic, and therapeutic considerations. Ann Intern Med 1984:100:92-106.

${ }^{5}$ Lerner CW, Tapper ML. Opportunistic infection complicating acquired immune deficiency syndrome. Medicine (Baltimore) 1984:63:155-64.

${ }^{6}$ Fahey JL, Prince H, Weaver M et al. Quantitive changes in $\mathrm{T}$ helper or $\mathrm{T}$ suppressor/cytotoxic lymphocyte subsets that distinguish acquired immune deficiency syndrome from other immune subset disorders. Am J Med 1984:76:95-100.

${ }^{7}$ Hooper DC, Pruitt AA, Rubin RH. Central nervous system infection in the chronically immunosuppressed. Medicine (Baltimore) 1982:61:166-88.

${ }^{8}$ Levy RM, Pons VG, Rosenblum ML. Central nervous system mass lesions in the acquired immunodeficiency syndrome (AIDS). J Neurosurg 1984:61:9-16.

${ }^{9}$ Pitchenik AE, Fischl MA, Walls KW. Evaluation of cerebral-mass lesions in acquired immunodeficiency syndrome (letter). $N$ Engl J Med 1983:308:1096.
${ }^{10}$ Post MJD, Chan JC, Hensley GT, Hoffman TA, Moskowitz LB, Lippman S. Toxoplasma encephalitis in Haitian adults with acquired immunodeficiency syn- $\mathbb{D}$

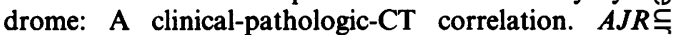
1983:140:861-8.

${ }^{11}$ Moskowitz LB, Hensley GT, Chan JC, Gregorios J, Conley FK. The neuropathology of acquired immune deficiency syndrome. Arch Pathol Lab Med 1984:108: O) 867-72.

12 Wong B, Gold JWM, Brown AE, et al. Central-nervoussystem toxoplasmosis in homosexual men and par- $\overrightarrow{2}$ enteral drug abusers. Ann Intern Med 1984:100:36-42.

${ }^{13}$ Cornell SH, Jacoby CG. The varied computed tomographic appearance of intracranial cryptococcis. Radiology 1982:143:703-7.

${ }^{14}$ Fujita NK, Reynard M, Sapico FL, Guze LB, Edwards 음 JE. Cryptococcal intracerebral mass lesions. The role of $\frac{\bar{\sigma}}{\partial}$ computed tomography and nonsurgical management. Ann Intern Med 1981:94:382-8.

15 Arrington JA, Murtagh FR, Martinez CR, Schnitzlein ${ }^{\infty}$ HN. CT of multiple intracranial cryptococcoma. AJNR 1984:5:472-3.

${ }^{16}$ Whelan MA, Kricheff II, Handler M, Ho V, Crystal K, Gopinathan G, Laubenstein L. Acquired immunodeficiency syndrome: cerebral computed tomographic $\bar{F}$ manifestations. Radiology 1983:149:477-84.

${ }^{17}$ Luft BJ, Brooks RG, Conley FK, McCabe RE, Remington JS. Toxoplasmic encephalitis in patients $\omega$ with acquired immune deficiency syndrome. JAMGA 1984:252:913-7.

${ }^{18}$ Moskowitz LB, Hensley GT, Chan JC, Conley FK, Pøit을 MJD, Gonzales-Arias SM. Brain biopsies in patierfs -

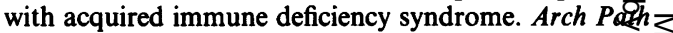
Lab Med 1984:108:368-71. 